\title{
Clinical Picture
}

\section{Saccular aneurysm within a persistent ductus arteriosus}

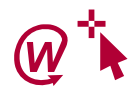

Denise van der Linde, Maarten Witsenburg, Ingrid van de Laar, Adriaan Moelker, Jolien Roos-Hesselink

A 26-year-old man with a proven SMAD3 mutation underwent cardiovascular assessment, because his 52-year-old mother died of an aortic dissection and his 28-year-old brother has an aortic root aneurysm of $41 \mathrm{~mm}$. CT angiography showed a dilated pulmonary trunk $(50 \mathrm{~mm})$ and a saccular aneurysm of a persistent ductus arteriosus (figure A; see also webvideo 1). During catheterisation the pressure in the aneurysm was $75 \%$ of systemic arterial pressure. To prevent further enlargement and possible rupture, the aneurysm $(18 \mathrm{~mm} \times 14 \mathrm{~mm})$ was filled with an Amplatzer Vascular Plug II (AGA Medical,
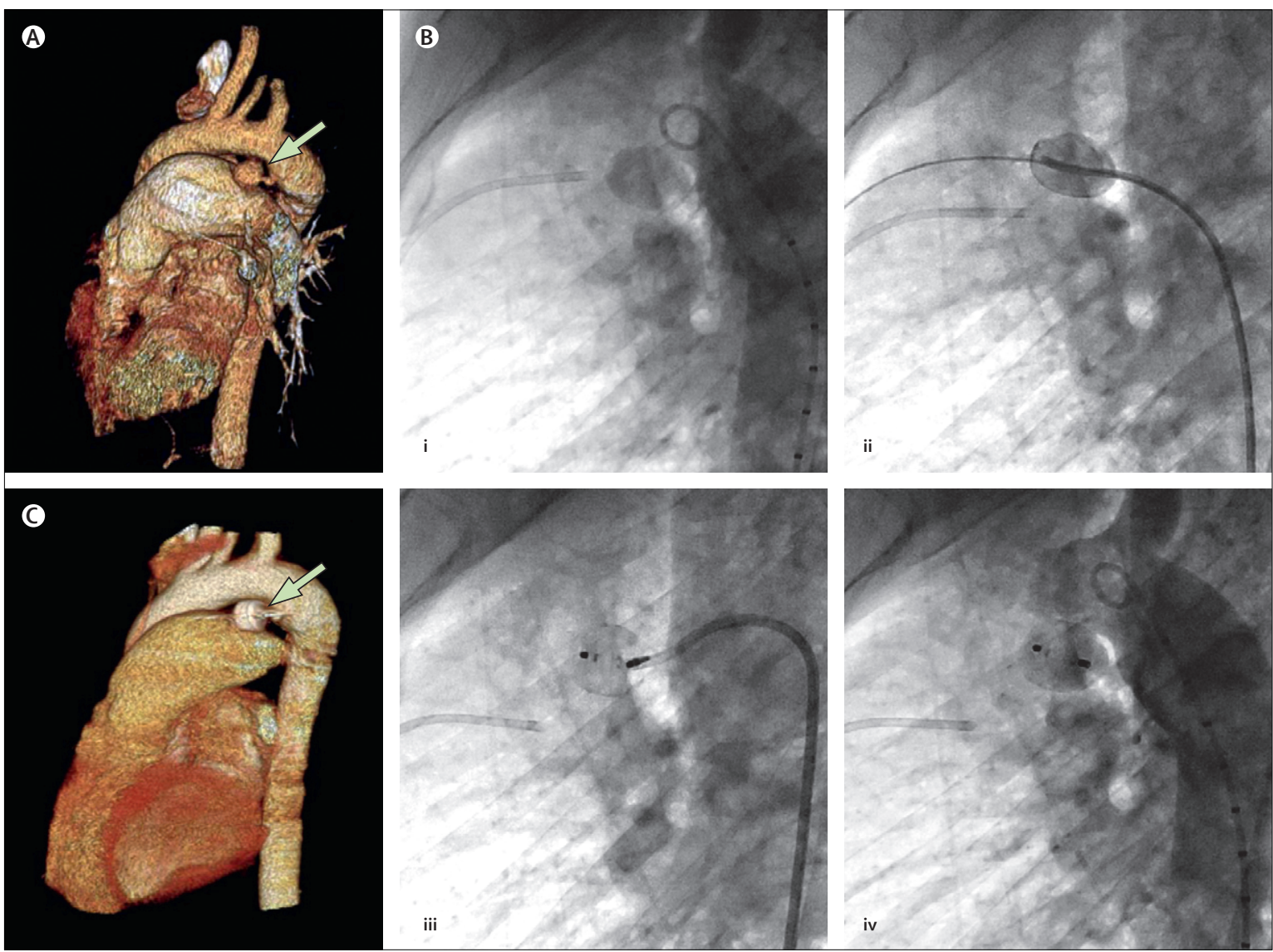

Lancet 2012; 379: e33 Published Online December 16, 2011 DOI:10.1016/S01406736(11)61352-4

Department of Cardiology (D van der Linde MSC $M$ Witsenburg MD, ProfJ Roos-Hesselink MD) Department of Clinical Genetics (I van de Laar MD), and Department of Radiology (A Moelker MD), Erasmus Medical Centre, Rotterdam Netherlands

Correspondence to: Prof Jolien Roos-Hesselink Department of Cardiology, Erasmus Medical Centre, Gravendijkwal 230, Rotterdam, Netherlands j.roos@erasmusmc.nl

See Online for webvideos

Figure: Saccular aneurysm within a persistent ductus arteriosus and placement of a vascular plug

(A) 3D reconstruction of CT angiography showing a dilated pulmonary trunk (50 $\mathrm{mm}$ ) and a saccular aneurysm of a persistent ductus arteriosus (arrow). (B) Angiography images showing different stages of catheterisation: (i) aneurysm of the persistent ductus arteriosus (14 mm $\times 18 \mathrm{~mm}$ ); (ii) catheter positioned within the aneurysm; (iii) delivery of the vascular plug (size $16 \mathrm{~mm} \times 12 \mathrm{~mm}$ ); (iv) closure of the persistent ductus arteriosus with the vascular plug in place. (C) 3D reconstruction of CT angiography showing the result after interventional closure of the aneurysm with a vascular plug (arrow). 